GLOBAL JOURNAL OF ENGINEERING RESEARCH VOL 11, NO. 1, 2012: 1-10

COPYRIGHTC BACHUDO SCIENCE CO. LTD PRINTED IN NIGERIA. ISSN 1596-292x www.globaliournalseries.com; Info@globaljournalseries.com

\title{
DESIGN, CONSTRUCTION AND TESTING OF AN UNINTERRUPTIBLE POWER SUPPLY OF 300 WATTS CAPACITY
}

\section{JAMES O. USHIE, EYO O. UKEM AND BRIAN E. USIBE}

(Received 7, February 2012; Revision Accepted 5, April 2012)

\begin{abstract}
The interruption of power supply is a source of concern to the consumer, and gives rise to the need to provide emergency power source in some important areas of both domestic and industrial application. This has led to the design and construction of the Uninterruptible Power Supply (UPS). In this work, we made use of solid state components, with the aid of background knowledge in the field of electronics, to locally manufacture a UPS which could be used for back-up power for critical and essential loads. For the design, a battery is used to provide direct voltage and current, which is inverted by the inverter. The inverted $12 \mathrm{v}$ a.c., $50 \mathrm{~Hz}$, is transformed using the transformer to $240 \mathrm{v}$ a.c., $50 \mathrm{~Hz}$. The system also has in-built voltage reversal protection, automatic change-over and battery charger, which recharges the battery for continuous use when mains supply is restored. The output power of the constructed device was found to be 290 watts (determined by power transistor), which gives a percentage error of 3.3\%.
\end{abstract}

KEYWORDS: Power interruption, emergency supply, battery, inverter, automatic control.

\section{INTRODUCTION}

Every electrical and electronic equipment needs to be energised by means of a power supply. In most cases the power is required to be delivered to the load circuit at steady or fixed voltage. However, stability of such main power supply is a source of concern because insufficiency and accompanying power outage have always posed major setbacks to individuals and organizations which depend on sensitive electronic equipment that require constant power supply. Such interruption of mains supply has caused serious inconveniences especially in highly sensitive devices such as computers, medical equipment and industrial research laboratories where interruption of power could spell danger. Power outage is an unavoidable phenomenon and the need for reliable back up or emergency power supply system cannot be overemphasised, which is what has led to the design of this project. In order to protect such sensitive electronic systems from inactivity resulting from power failure, it is necessary to provide an alternative power source, which will automatically power the system in the event of mains failure. Though the likes of the unit are in the market, they have an operation period in the range of 30 minutes to 1 hour and are mostly imported, which is not exactly suitable for our present power supply environment (Musa and Chukwurah, 2001). The objective of this article is to present a UPS that has been designed and built to overcome some of these setbacks by having an operation period or autonomy of up to 2 hours.

Some systems that perform similar functions to the UPS exist. One of such is the Storage Battery-Emergency DC System. This system is used primarily for emergency lighting, fire alarms and emergency communications systems. It consists of an automatic charger, a battery and an emergency dc bus. It is statutorily required that the system be capable of maintaining the total load for a period of one and half hours minimum without the load voltage

James O. Ushie, Department of Physics, University of Calabar, Calabar, Nigeria

Eyo O. Ukem, Department of Physics, University of Calabar, Calabar. Nigeria

Brian E. Usibe, Department of Physics, University of Calabar, Calabar. Nigeria 
falling below $87.5 \%$ of normal. (Kusko, 1989). Another such system is the Engine Generator System. This system typically consists of the petrol or diesel engine or a gas or steam turbine and an ac synchronous generator control. It is always incorporated with a transfer switch manual or automatic. This switch is normally set to transfer the load to the set 10 seconds after the engine is started (Kusko, 1989). Whenever there is power outage, the engine is started either manually or automatically. As soon as the generator output reaches nominal voltage and frequency, the transfer switch operates to connect the load to the set. When the main power returns, the transfer switch is operated automatically to return the load to the utility main supply, (Barnett, 1987).

\section{MATERIALS AND METHOD}

This section of the article deals with the actual design analysis, calculations and how some component values were obtained using some fundamental theories and modelling. The block diagram of the proposed complete UPS circuit is shown in Figure 1. The major sections are the battery, the battery charger, the inverter, and a change-over switch.

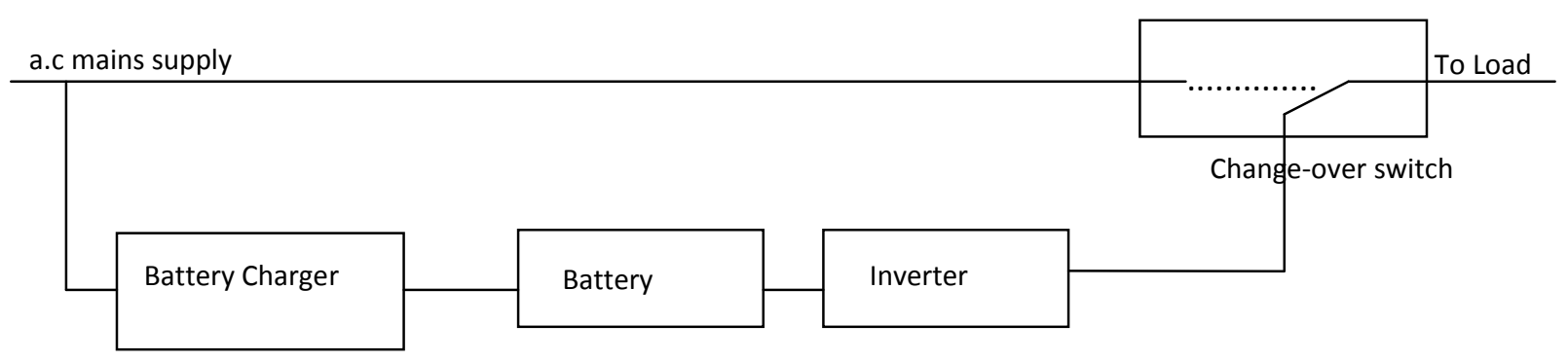

Figure 1: Proposed Block Diagram of UPS

During normal operation, in the presence of mains supply, power is delivered directly to the load through the change-over switch. At the same time the mains supply is used, with the aid of the battery charger, to maintain a float charge over the battery. Thus the battery remains fully charged. When mains supply is interrupted, the change-over switch connects the load to inverter. The battery d.c. output is converted to a.c. by the inverter and used to power the load. Thus the battery effectively takes over and supplies power to the load. During this time the battery inevitably discharges, and the autonomy of the system depends on how long the battery output remains above a certain specified level. On restoration of mains power the change-over switch returns the load to the direct line and the battery charger recharges the battery.

INVERTER: The heart of the UPS is the inverter. An inverter is an electrical device that converts direct current (DC) to alternating current (AC) (Moise and others, 2000). The process of converting dc into ac is known as Inversion (the reverse of rectification). Thus an inverter is a device or circuit that changes dc power into ac power or in other words an inverter is an inverted converter, (Owen, 1996). The inverter incorporates an astable multivibrator which generates a square wave (the a.c. voltage) at a required frequency, a frequency reduction circuit, a Darlington pair to match the signal to a power transistor which in turn determines the power rating of the system. There is also a voltage regulator to regulate the d.c. voltage supplied to the various components and also serve as a link between the battery and the components, and a transformer to step up the output voltage to required levels.

VOLTAGE REGULATOR: A change in voltage from no-load condition is known as voltage regulation. This happens in unregulated power supplies where the output voltage is never constant. It changes with supply voltage or load resistance. Hence, the purpose of voltage regulator circuit is to reduce the output voltage variations to zero or at least to minimum possible value (Theraja, 2000). Percentage Regulation, \% Reg, is given as:

$\% \operatorname{Reg}=\left(\left(\mathrm{V}_{\max }-\mathrm{V}_{\min }\right) / \mathrm{V}_{\max }\right) \times 100$

where $\mathrm{V}_{\max }=$ maximum d.c. output voltage and $\mathrm{V}_{\min }=$ minimum d.c. output voltage. 
555 - TIMER ASTABLE MULTIVIBRATORS

(MV): The 555-timer is an IC with dozens of different functions including astable operation.
Figure 2 shows a POWER SUPPLY OF 555timer connection for astable operation. It runs freely at a frequency determined by $R_{A}, R_{B}$ and $C$.

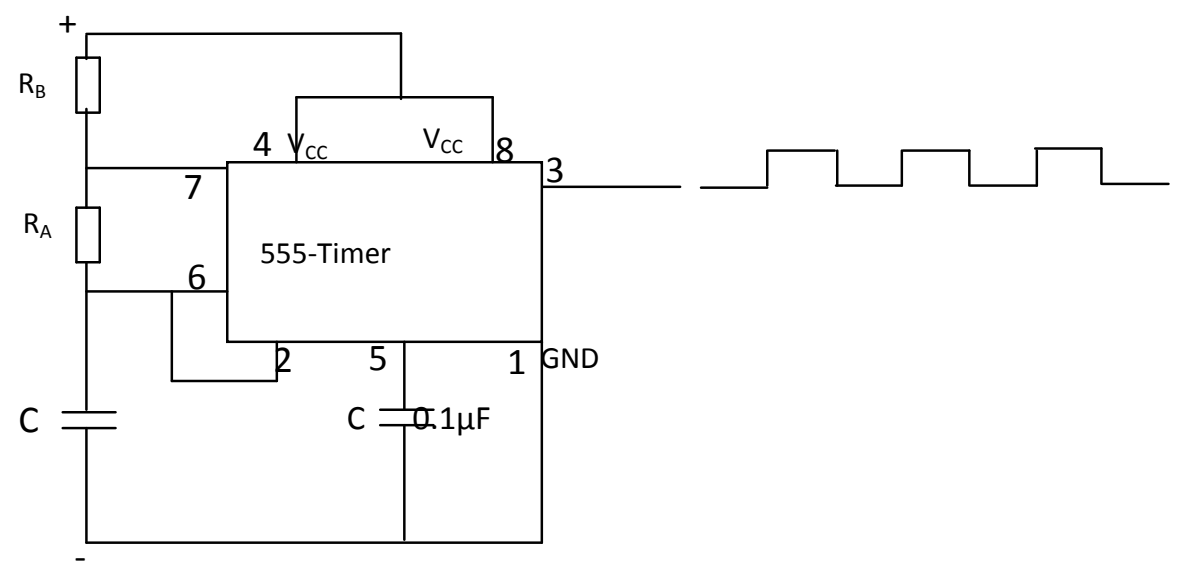

Figure 2: 555-Timer IC

The duration of the high state is $T_{H}=0.693\left(R_{A}+R_{B}\right) C$ while the duration of the low state is $T_{L}=$ $0.693 R_{B} C$. Therefore, the period, $T$, of the rectangular output is

$T=0.693\left(R_{A}+2 R_{B}\right) C$

and frequency, $f$, is

$f=1 / T=1 /\left(0.693\left(R_{A}+2 R_{B}\right) C\right)=1.44 /\left(\left(R_{A}+2 R_{B}\right) C\right)$

For this problem, it is desired to have a final output frequency of $50 \mathrm{~Hz}$ from the inverter. The astable multivibrator output frequency is therefore selected to be $200 \mathrm{~Hz}$, which can easily be reduced to $50 \mathrm{~Hz}$ making use of frequency reduction circuitry. For convenience, $R_{A}$ is selected to be $10 \mathrm{k}$ and the capacitor $\mathrm{C}$ to be $0.1 \mu \mathrm{F}$. From equation $2, \mathrm{R}_{\mathrm{B}}$ can be calculated thus:

$\mathrm{T}=0.693\left(\mathrm{R}_{\mathrm{A}}+2 \mathrm{R}_{\mathrm{B}}\right) \mathrm{C}$

$=\quad 0.693 R_{A} C+2 \times 0.693 R_{B} C$

Hence $2 \times 0.693 R_{B} C=T-0.693 R_{A} C$

and $R_{B}=\left(T-0.693 R_{A} C\right) / 2 \times 0.693 C$

Now, $f=200 \mathrm{~Hz}$, therefore $T=1 / \mathrm{f}=1 / 200=0.005 \mathrm{sec}=5 \times 10^{-3} \mathrm{sec}$.

$\mathrm{R}_{\mathrm{A}}=10 \mathrm{k}=10 \times 10^{3}$ and $\mathrm{C}=0.1 \mu \mathrm{F}=0.1 \times 10^{-6} \mathrm{~F}$

Therefore, $R_{B}=\left(T-0.693 R_{A} C\right) / 2 \times 0.693 C$

$=\quad\left(5 \times 10^{-3}-0.693 \times 10 \times 10^{3} \times 0.1 \times 10^{-6}\right) /\left(2 \times 0.693 \times 0.1 \times 10^{-6}\right)$

$=(4.307 / 0.1386) \times 10^{3}=31 \mathrm{k}$

Using these values, we find that:

$\mathrm{T}_{\mathrm{L}}=0.693 \times 31 \times 10^{3} \times 0.1 \times 10^{-6}=2.1483 \times 10^{-3} \mathrm{sec}$, and

$\mathrm{T}_{\mathrm{H}}=0.693(31+10) \times 10^{3} \times 0.1 \times 10^{-6}=2.8413 \times 10^{-3} \mathrm{sec}$

Therefore $T=T_{H}+T_{L}=(2.1483+2.4813) \times 10^{-3}=4.9896 \times 10^{-3}=5 \times 10^{-3} \mathrm{sec}$.

and $f=1 / T=1 /\left(5 \times 10^{-3}\right)=200 \mathrm{~Hz}$ 
FREQUENCY REDUCTION CIRCUIT: Dual JK flip-flops (FF) are used in frequency reduction as shown in Figure 3 below. Each FF has its $\mathrm{J}$ and $\mathrm{K}$ input go from ON to OFF. The clock pulses are applied only to the clock input of $F F Q_{0}$. Output $Q_{0}$ is connected to the clock input of $F F Q_{1}$. The following important points should be noted:

- $F F Q_{0}$ toggles on the negative-going transition of each input clock pulse. Thus the $Q_{0}$ output waveform has a frequency that is exactly one-half of the clock pulse frequency.

- $F F Q_{1}$ toggles each time the $Q_{0}$ output goes from high to low. The $Q_{1}$ waveform has a frequency equal to one-half of frequency of $Q_{0}$ output and therefore one-fourth of the clock frequency.

- Each FF output is a square wave (50 percent duty circle)

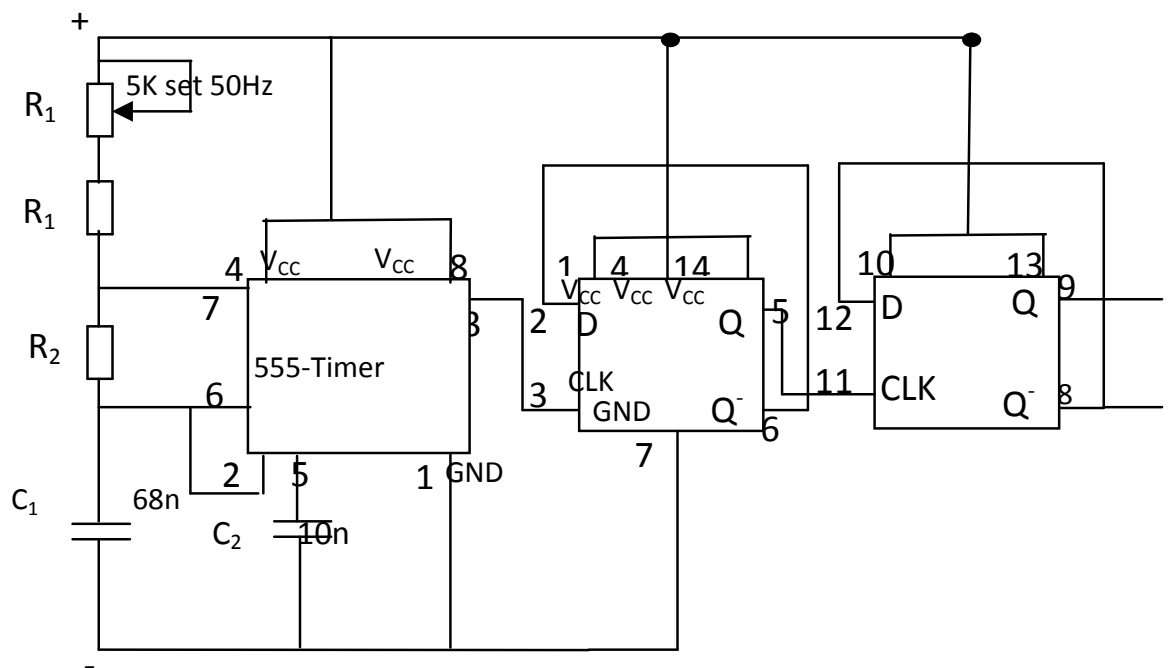

Figure 3: 555-Timer and Dual Flip-Flop (DFF) for $50 \mathrm{~Hz}$ Generation

DARLINGTON PAIR: One way to boost input impedance is to use transistors in a Darlington pair configuration. Darlington pair circuits are widely used as current amplification in d.c power supplies and the input stages of op-amp integrated circuits (Maddock \&Calcuit, 1995). As shown in Figure 4, the collectors of two transistors are connected or held to $+\mathrm{V}_{\mathrm{CC}}$ and the emitters of the first drive the base of the second. This configuration achieves $\beta$ (current gain) multiplication as shown in the following step.

The emitter current of the first transistor $Q$ is $I_{e 1}=\beta_{1} l b_{1}$. This emitter current of $Q_{1}$ becomes the base current of $Q_{2}$, producing a second emitter current. $\mathrm{l}_{\mathrm{e} 2}=\beta_{2} \mathrm{l}_{\mathrm{e} 1}=\beta_{1} \beta_{2} \mathrm{lb}_{1}$. 

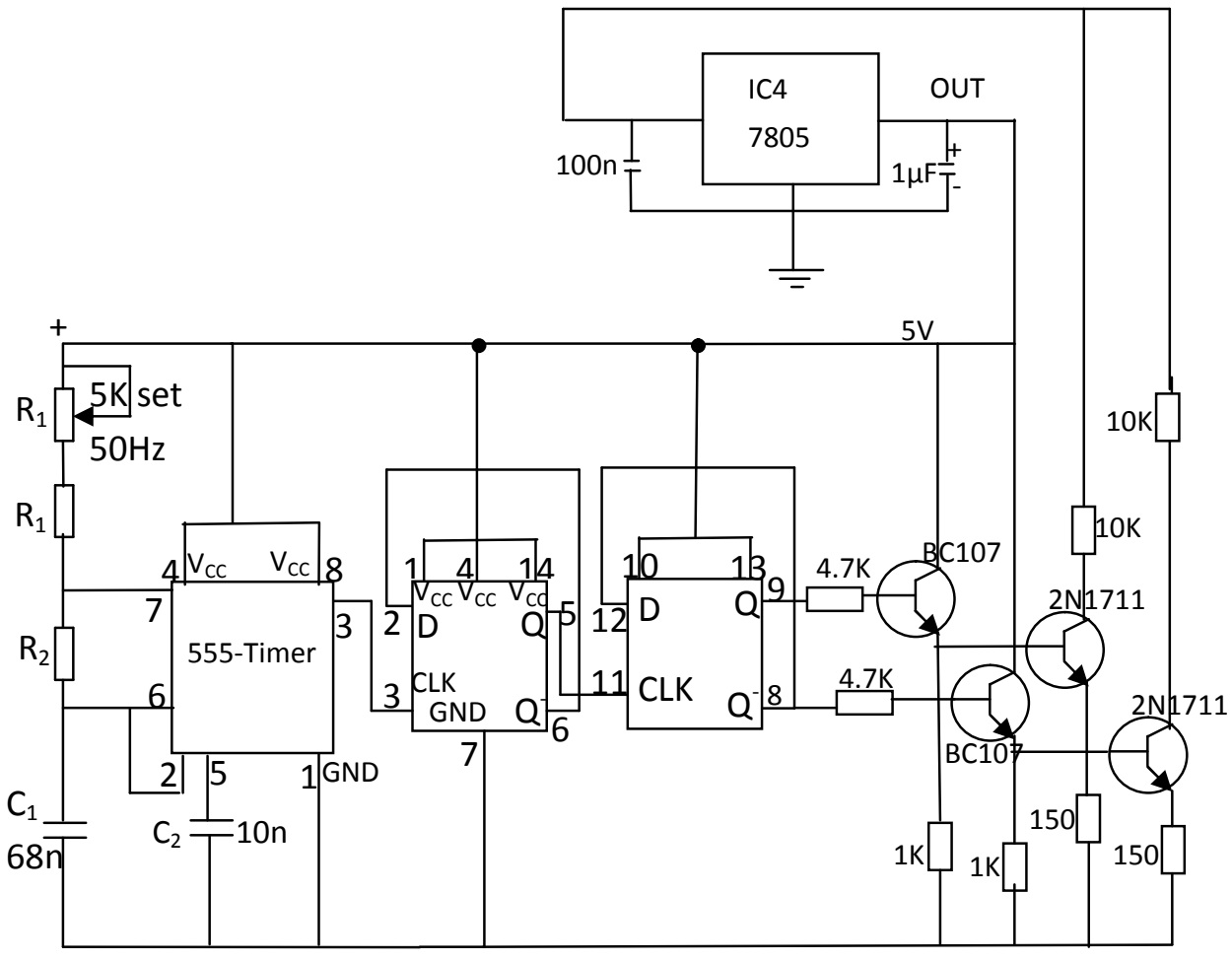

Figure 4: 555-Timer, DFF and Darlington Pair

The complete inverter circuit, made up of the just described components, is shown in Fig. 5.

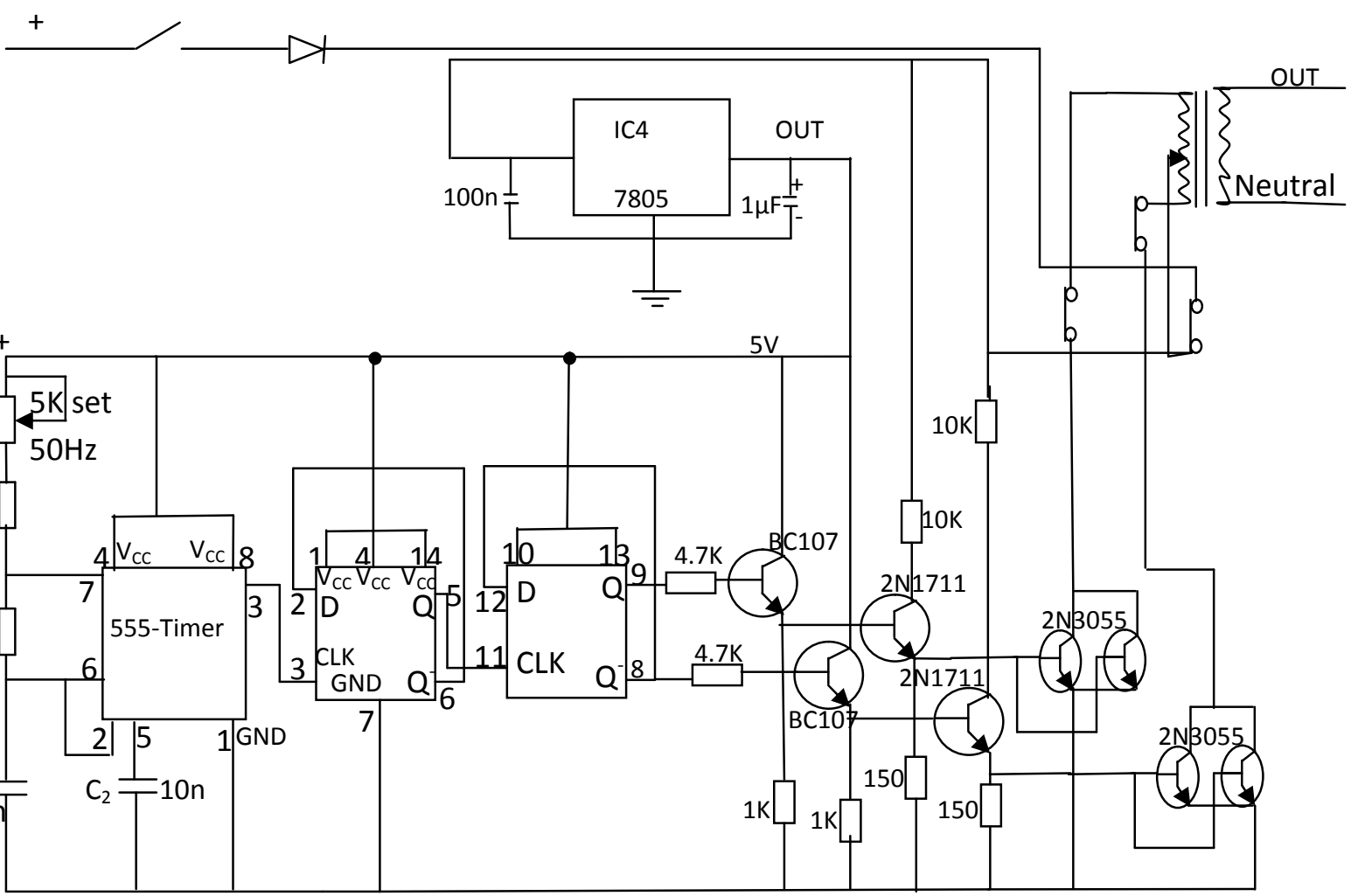

Figure 5: Inverter Circuit 


\section{INVERTER AND AUTOMATIC CONTROL CIRCUIT}

The control circuit is comprised mainly of a relay or contactor, which is an electromagnetic device which can often be activated by little energy, causing a movable ferromagnetic armature to open or close one or several pairs of electrical contact points located in another control circuit or in a main circuit handling large energy. Figure 6 below shows a typical contactor incorporated in the inverter circuit. When a current is applied to the contactor coil, the iron arm is attracted to the pole face of the contactor coil, and when the current is interrupted the arm is returned to its normal position by the spring. The arm can then be used to close or open a set of contacts. In this project the control circuit is connected such that when mains supply is available the arm is positioned so as to connect the load to the mains directly, and when mains supply is interrupted the arm is positioned so that the inverter output is connected to the load, through the transformer. Only one supply at a time - mains or inverter - is connected to the load at any one time.

\section{BATTERY CHARGER / RECTIFIER}

Full wave bridge rectifier is employed in this project. It required a step down transformer 240/15 volts, four diodes IN4001, connected as shown in Figure 7, which forms the complete circuit diagram for the UPS. Rectifier circuits are often classified by the number of current pulses that flow to the DC side of the rectifier per cycle of $A C$ input voltage. A_single-phase half-wave rectifier is a one-pulse circuit and a single-phase full-wave rectifier is a two-pulse circuit. A threephase half-wave rectifier is a three-pulse circuit and a three-phase full-wave rectifier is a six-pulse circuit, (Grafham and Hey, 1972).
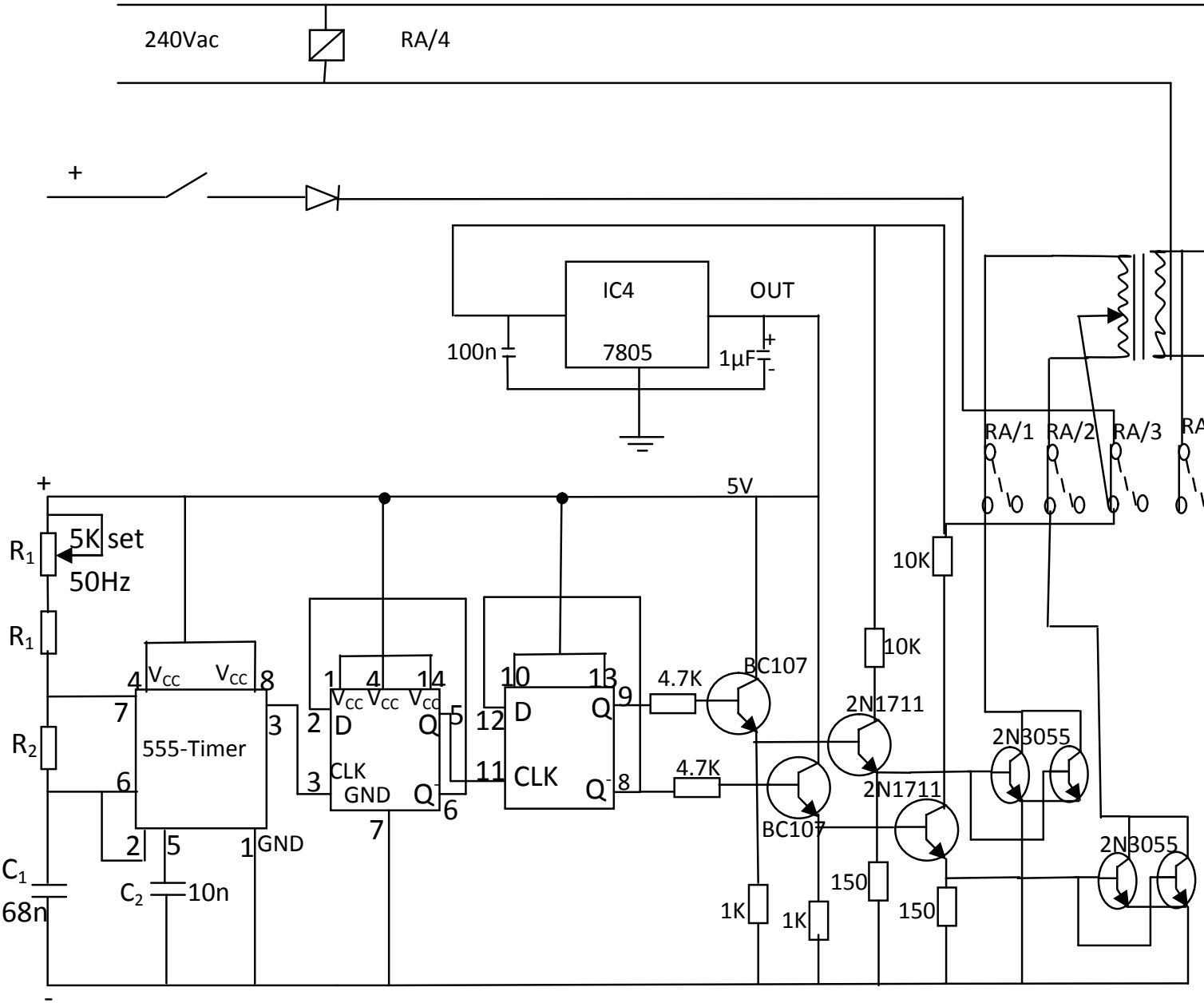

Figure 6: Inverter and Automatic Control Circuit 

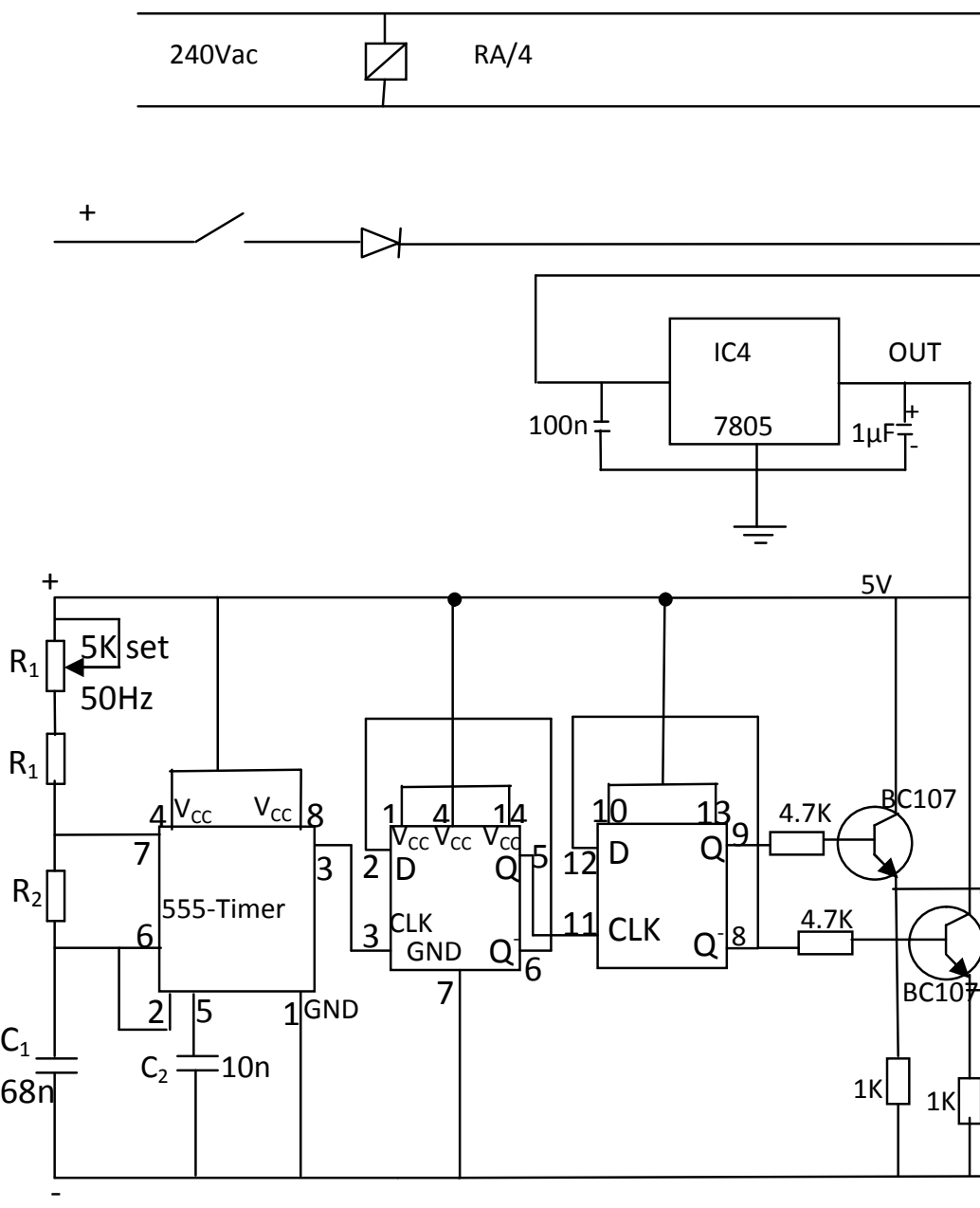

Figure 7: Uninterruptible Power Supply Circuit

\section{RESULT AND DISCUSSION}

In order to assess the performance of the UPS, some measurements were taken for each of the four earlier named subunits. Two phases of tests were carried out, the first being on breadboard and the second after soldering on Vero board. The final testing was that on the entire system after having coupled the subunits together. Equipment used for the testing included digital multimeter (with frequency), d.c power supply, oscilloscope and analogue multimeter.
The specific tests carried out included (i) continuity test (ii) component status test (iii) unit test and (iv) complete system test. In continuity test, analogue metre set at resistance was used to check for short circuits and open circuits between conductors/wire and also to detect partial contacts. Some of the wave shapes displayed on the oscilloscope during the unit tests are presented in Figure 8. The A display is the output of the astable multivibrator while $B$ and $C$ are the output from various stages of the frequency reducing circuit. 


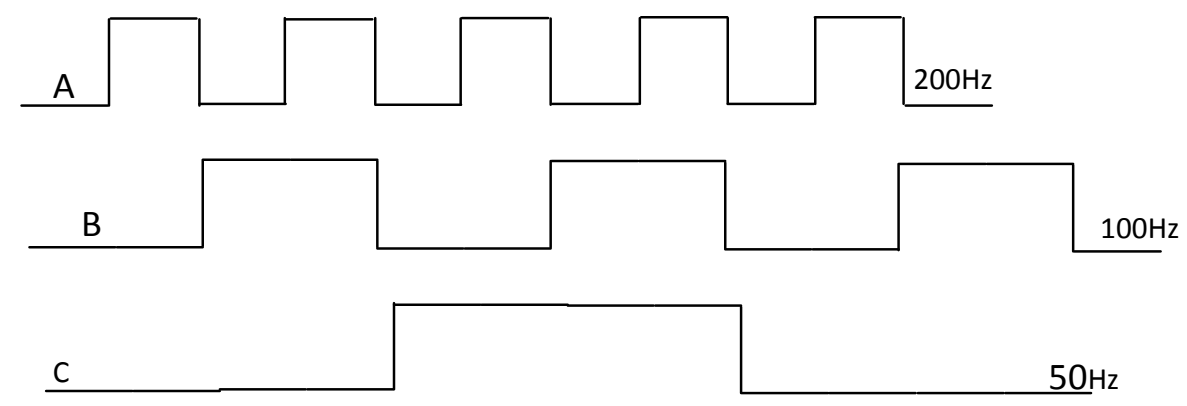

Figure 8: Waveform as seen on Oscilloscope, Measurements being taken at Output Number 3 for $\mathrm{A}, 5$ for $\mathrm{B}$ and 8 or 9 for $\mathrm{C}$

The complete system consists of the four units interfaced together to form one UPS that generates a sinusoidal voltage from d.c. source (with mains supply OFF) while recharging the d.c. source on mains (mains ON). Using a $120 \mathrm{Ah} / 12 \mathrm{~V}$ d.c. car battery for the test, the inverter produced alternating voltage from the $12 \mathrm{~V}$ d.c. source. The charger output was $15 \mathrm{~V}$ d.c, $5 \mathrm{~A}$ when loaded and tested. The contactor was also tested and found to be working very well.

Digital multimetre was used to verify the theoretical/specified characteristic of each component.

\section{BATTERY PERFORMANCE AND TEST RESULTS}

In order to give information as regards the backup time available for the system the following measurements were taken: input (battery voltage with time) and output (inverter voltage with time). The results obtained are as shown in Table 1. This uninterruptible power supply unit when compared to its model counterparts found in the market, goes for longer hours that can supplement and serve as a backup power to mains supply for a time period specified by the client. The system is of great importance for all fields of life including military, hospital, airport, telex system etc. Besides, it is also mostly needed in computer environment, where information storage is given priority. 
Table 1: Inverter input voltage and inverter output voltage with time.

\begin{tabular}{|l|l|l|}
\hline Time in minutes & $\begin{array}{l}\text { Battery d.c. voltage } \\
(\mathrm{V})\end{array}$ & $\begin{array}{l}\text { Inverter output a.c. } \\
\text { voltage (V) }\end{array}$ \\
\hline 0 & 12.41 & 250 \\
\hline 15 & 12.40 & 246 \\
\hline 30 & 12.39 & 244 \\
\hline 45 & 12.37 & 240 \\
\hline 60 & 12.35 & 238 \\
\hline 75 & 12.24 & 236 \\
\hline 90 & 12.15 & 235 \\
\hline 105 & 12.12 & 228 \\
\hline 120 & 12.08 & 223 \\
\hline 135 & 12.01 & 218 \\
\hline 150 & 11.97 & 215 \\
\hline 165 & 11.94 & 214 \\
\hline 180 & 11.88 & 212 \\
\hline 195 & 11.84 & 208 \\
\hline 210 & 11.80 & 200 \\
\hline 225 & 10.90 & 186 \\
\hline 240 & 10.84 & 170 \\
\hline
\end{tabular}

\section{CONCLUSION}

UPS is a device used for back-up power for critical and essential loads. The design of the UPS from discrete components based on the principle that any system that can generate pulsating alternating waveform of any regular shape (sawtooth, ramp, square, sinusoidal) with appropriate mark to space ratio from a d.c source, can be used to generate pure or almost clean a.c. signals. The waveform generator was 555-timer configured in the astable mode. The square waveform produced was rounded to near sinusoidal waveform by transistor amplification and switching.

The aim of this project work, which was to design and construct a reliable UPS system for lower power domestic use was achieved. When tested, the system functioned as anticipated according to design. It achieved very fast load transfer between mains power and battery power on mains failure, and again between back-up power and mains power or restoration of mains power.

\section{REFERENCES}

Barnett, P., 1987. Changing Trends in the Design of Uninterruptible Power Supply, IEE
Journal Electronics and Power 33, (7PP): 457-460. July 1987.

Grafham, D. R and Hey, J. C., 1972. editors, ed SCR Manual (Fifth ed.). Syracuse, N.Y. USA: General Electric. pp. 236-239.

Kusko, Alexander., 1989. Emergency/Standard Power Systems, New York: Mc Grew-Hill Book Company.

Maddock, R. J and Calcutt, D. M., 1995. Electronics, A Course for Engineers $2^{\text {nd }}$ Edition, London: Longman Scientific and Technical.

Moise, A., Anderson, M., Tucker, R. D., Penn, T. $L$ and Orr, P., 2000. The Authoritative Dictionary of IEEE Standards Terms, Seventh Edition, IEEE Press, 2000, 588.

Musa, A. E and Chukwurah., 2001. A 24 Hours Uninterrupted Power Supply Unit (UPS) Conference on New Product and Technologies for SMEs, May $21-23$, 2001, Benin City, Nigeria.

Owen, Edward L. (January/February 1996). "Origins of the Inverter". IEEE Industry 
Applications Magazine:

Department (IEEE) 2, (1): 64-66.

Theraja, B. K. and Theraja, A. L., 2000. A Textbook on Electrical Technology $22^{\text {nd }}$ Edition, New Delhi S. S. Chaud Publishers Limited. 